University of Nebraska - Lincoln

DigitalCommons@University of Nebraska - Lincoln

March 1997

\title{
Converging Evidence for One-Trial Context Fear Conditioning With an Immediate Shock: Importance of Shock Potency
}

Rick A. Bevins

University of Nebraska-Lincoln, rbevins1@unl.edu

Janice E. McPhee

University of Massachusetts at Amherst

Anthony S. Rauhut

University of Massachusetts at Amherst

John J.B. Ayres

University of Massachusetts at Amherst

Follow this and additional works at: https://digitalcommons.unl.edu/psychfacpub

Part of the Psychiatry and Psychology Commons

Bevins, Rick A.; McPhee, Janice E.; Rauhut, Anthony S.; and Ayres, John J.B., "Converging Evidence for One-Trial Context Fear Conditioning With an Immediate Shock: Importance of Shock Potency" (1997). Faculty Publications, Department of Psychology. 198.

https://digitalcommons.unl.edu/psychfacpub/198

This Article is brought to you for free and open access by the Psychology, Department of at DigitalCommons@University of Nebraska - Lincoln. It has been accepted for inclusion in Faculty Publications, Department of Psychology by an authorized administrator of DigitalCommons@University of Nebraska - Lincoln. 
Published in Journal of Experimental Psychology: Animal Behavior Processes, Vol. 23 (1997), No. 3, pp. 312-324. Copyright (C) 1997 by the American Psychological Association. Inc.http://www.apa.org/journals/xan/ "This article may not exactly replicate the final version published in the APA journal. It is not the copy of record." Used by permission.

\title{
Converging Evidence for One-Trial Context Fear Conditioning With an Immediate Shock: Importance of Shock Potency
}

\author{
Rick A. Bevins \\ University of Nebraska-Lincoln \\ Janice E. McPhee, Anthony S. Rauhut, and John J. B. Ayres \\ University of Massachusetts at Amherst
}

\begin{abstract}
In a sample of 208 Holtzman-descended albino rats, we found evidence with 4 measures of conditioning (freezing, defecation, side crossing, and nose crossing) that a single 2-s, 1.0-mA immediate shock could condition fear to a context (Experiments $1,2$, and 4$)$. When we reduced the shock intensity to $0.5 \mathrm{~mA}$, we obtained a complete immediate-shock conditioning deficit according to all measures in Experiment 3 and to all but the defecation measure in Experiment 4. Results suggest two conclusions: (a) Differences in shock potency between laboratories may help explain discrepant findings about whether immediate shock supports contextual conditioning; (b) theories of contextual conditioning need a mechanism that permits that conditioning to result from immediate shock.
\end{abstract}

Recently, considerable interest has developed about understanding the neural and behavioral processes mediating onetrial context fear conditioning (e.g., Bevins \& Ayres, 1994, 1995; Fanselow, 1986, 1990; Fanselow, DeCola, De Oca, \& Landeira-Fernandez, 1995; Fanselow, DeCola, \& Young, 1993; Kiernan, Westbrook, \& Cranney, 1995; Landeira-Fernandez, Fanselow, DeCola, \& Kim, 1995; Maes \& Vossen, 1992; Westbrook, Good, \& Kiernan, 1994). This interest is fueled, in part, by the belief that identifying the underlying processes will bring the field closer to answering some long standing questions: How do animals process contextual stimuli? What constitutes a context versus a stimulus element? Do the rules for the conditioning of contextual stimuli resemble those for the conditioning of discrete stimulus elements?

Some of the research in this area has focused on an effect termed the immediate-shock freezing deficit. Fanselow (1986)

This work was funded by a faculty research grant from the University of Massachusetts at Amherst and National Institute of Mental Health Grant MH50491-01. Dissertation funds from the Psychology Department at University of Massachusetts at Amherst, in part, funded Experiment I. Rick A. Bevins was supported by National Research Service Award Grant DA05623 from United States Public Health Service while preparing the manuscript for publication.

The data in this article were described by Janice E. McPhee at the 1996 meeting of the Eastern Psychological Association, Philadelphia. We thank Michelle Wynn for her help in scoring behavior in Experiment 4.

Correspondence concerning this article should be addressed to Rick A. Bevins, Department of Psychology, University of Nebraska-Lincoln, Lincoln, Nebraska 68588-0308, or to John J. B. Ayres, Psychology Department, University of Massachusetts, Tobin Hall, Amherst, Massachusetts 01003. Email: rbevins1@unl.edu or joeayres@psych.umass.edu. coined this term to refer to the complete lack of conditioning (as assessed by conditioned immobility or freezing) to a distinct environment (context) in which a rat was given the immediate-shock procedure. The immediate-shock procedure entails delivering a single footshock to a rat immediately on its placement into a context. In a subsequent test for conditioning, the rat is reintroduced to the context and its behavior is observed.

The complete absence of context conditioning with the immediate-shock procedure, however, is not a universal finding. The original report by Blanchard, Fukunaga, and Blanchard (1976) and more recent work (Bevins \& Ayres, 1994, 1995) has suggested that the immediate-shock deficit is better described as partial. For instance, Blanchard et al. (1976), by using movement as a measure of context conditioning, reported significantly less movement by rats that received an immediate shock than by rats that did not experience a footshock. Moreover, Bevins and Ayres (1994, 1995); by using contextevoked freezing, found more freezing in rats given the immediate-shock procedure than in rats given a no-shock or a shock-alone control procedure.

Determining whether the immediate-shock deficit is better described as complete or partial and identifying the factors responsible for the discrepant effects of immediate-shock procedures have important implications for theories of context conditioning. Some behavioral and physiological theories of context processing and conditioning assume that no conditionable input (stimuli) is available immediately after an animal enters a new environment (e.g., Fanselow, 1990; Fanselow et al., 1993). This assumption is acceptable if the immediate-shock 
deficit reflects a complete lack of context conditioning. However, if immediate shock imparts some associative value to the context, then these theories would have to be modified.

Bevins and Ayres (1995) suggested several possible explanations for why they found weak but statistically significant context-fear conditioning following the immediate-shock procedure but Fanselow found no context conditioning (Fanselow, 1986, 1990; see also Kiernan et al., 1995). The present report examined two of these possibilities. First, there may be subtle differences in how the two laboratories scored freezing. To address this concern, we recorded additional, less subjective, measures of context conditioning in the four experiments reported here. We used an apparatus in which, during a 5-min test session, the rat could escape the conditioning chamber by entering a second chamber. Then, in addition to the usual measure of freezing, we recorded escape latency, side preference (total time spent on target side), side crossings (number of crossings from side to side), nose crossings (number of times the rat's nose crossed the line separating the two chambers), and defecation (total number of fecal boli). Measurements of escape latency, side preference, and side crossings were completely objective in that they were automatically recorded by a computer. If evidence for immediate-shock conditioning were consistently found with measures other than freezing, then concerns about subtle differences in the scoring of freezing would be inconsequential.

The second possibility assessed (indirectly) by the present study was that the different shock scramblers used by the two laboratories may deliver shocks that differ in their effectiveness. Fanselow $(1986,1990)$ used Grason-Stadler scramblers, whereas Bevins and Ayres (1995) used a Hoffman-Fleshler relay scrambler. Although the shock duration (2s) and nominal intensity $(1.0 \mathrm{~mA})$ were the same in both laboratories, we believe that the Hoffman-Fleshler scrambler delivers a more effective shock. In Experiment 3, we examined the potential importance of shock effectiveness by decreasing the shock intensity from $1.0 \mathrm{~mA}$ to $0.5 \mathrm{~mA}$. In Experiment 4, we directly compared the effects of these two intensities.

\section{Experiment 1}

Many authors have noted the importance of multiple dependent measures when drawing conclusions about learning (e.g., McAllister \& McAllister, 1971; Spear, Miller, \& Jagielo, 1990). Often, one measure will suggest a deficit or failure in learning, whereas another measure will reveal that robust learning did indeed occur. In this light, Experiment 1 collected a variety of measures of context conditioning in addition to the standard measure of freezing. The added measures should help us draw a stronger conclusion as to whether immediate shock can support such conditioning.

\section{Method}

Animals. The animals were 36 Holtzman-descended female albino rats (Rattus norvegicus). In this experiment and the remaining ex- periments, all rats used were bred in our colony at the University of Massachusetts, Amherst. Their weights ranged from 233 to $384 \mathrm{~g}$. All rats were housed singly in suspended stainless steel cages in a room kept on a 16:8-hr light-dark cycle. All treatments occurred in the light phase of this cycle. The rats had continuous access to food and water. On each of 5 days before the experiment, each rat was handled for about $1 \mathrm{~min}$.

Apparatus. Both sides (black and white) of a two-way shuttle box were used. The inside dimensions of the black side were $19.4 \times 20.3$ $\times 22.2 \mathrm{~cm}$ (height $\times$ width $\times$ length). The floor was made of 20 stainless steel rods, $2 \mathrm{~mm}$ in diameter, spaced $1.2 \mathrm{~cm}$ apart and mounted parallel to the end wall. The front wall was Plexiglas; the back wall and lid were also Plexiglas but with black cardboard mounted on the outside. The end wall was wood, painted glossy black. The wall separating the two sides of the shuttle box Was a metal plate, also painted glossy black. The litter tray was lined with gray corrugated cardboard. The black box was cleaned with a solution of $5 \%$ distilled vinegar (5\% acidity) and 95\% tap water before each rat was conditioned or tested.

The inside dimensions of the white side were the same as for the black side. The floor was made of nine aluminum strips, $1.3 \mathrm{~cm}$ wide, spaced $2.0 \mathrm{~cm}$ apart center to center. At each end of the floor was a stainless steel rod, $0.5 \mathrm{~cm}$ in diameter. The strips and rods were mounted parallel to the end wall. The front wall was Plexiglas; the back wall and lid were also Plexiglas but with white contact paper mounted on the outside. The metal dividing wall and the wooden end wall were painted flat white. The litter tray for the white side was lined with wood chips. The white box was wiped with tap water before each rat was conditioned or tested.

Ambient lighting was provided by a frosted white bulb $(100 \mathrm{~W}$, $120 \mathrm{~V}$ ) mounted about $30 \mathrm{~cm}$ in front of the front wall of the black side and about $27 \mathrm{~cm}$ above the grid floor. Masking noise of $68 \mathrm{~dB}$ was provided by a room air conditioner. A high-voltage, high-resistance shock source provided a $2-\mathrm{s}, 1.0-\mathrm{mA}$ grid-shock unconditioned stimulus (US) scrambled through a relay sequencing scrambler (Hoffman \& Fleshier, 1962). Rats were filmed with a Panasonic video camera (Model AG-180). A 28-V white indicator lamp (6 mm diameter) was mounted on a metal stand $(4 \mathrm{~cm}$ wide $\times 6 \mathrm{~cm}$ high) that shielded the light from the rat's direct view. It was centered just outside and below the front Plexiglas wall facing the camera. Throughout each session, it flashed on (1.9 s) and off ( $0.1 \mathrm{~s})$. Its flashing on the videotape was used to pace subsequent behavioral observations.

On the test day, the solid wall that divided the two boxes was replaced by a similar wall that had an $11.0 \times 7.3-\mathrm{cm}(\mathrm{h} \times \mathrm{w})$ opening cut in its bottom center. Switches mounted on each side of the box detected rat placement and side changes. For instance, when a rat was placed in the black side, the floor tilted, closed the switch, and sent a signal to a computer in an adjacent room. If the rat later moved to the white side, the floor tilted in that direction, closing the other switch. The floor was calibrated so that about half the rat's body had to cross the divider in order to close the switch on that side.

Procedure. Each rat was randomly assigned to one of three groups $(n s=12)$ : immediate (1), delay (D), or no shock (N). On Day 1, the rats in Group I received a 2-s, 1.0-mA grid shock immediately on placement and closure of the box lid. Placement of the rat into the black side, securing the lid, and removing the investigator's hand out of the rat's sight took about $2.5 \mathrm{~s}$. Thus, shock for rats in Group I occurred $2.5 \mathrm{~s}$ after closure of the floor switch (i.e., placement). Group $\mathrm{D}$ received the same shock in the black side $120 \mathrm{~s}$ after placement. Rats in both groups were removed $30 \mathrm{~s}$ after shock and returned to the colony. The control group, Group N, was treated like Group I but 
without the shock. On Day 2, all rats were placed in the black side and filmed for $5 \mathrm{~min}$. On this day, the divider with the opening was used, thus allowing rats full access to the novel white side.

Dependent measures. On the test day, conditioning was assessed in the shuttle box in terms of six dependent measures: freezing, defecation, number of side crossings, number of nose crossings, escape latency, and side preference.

Freezing was defined as the absence of movement except that of the rat's sides needed for breathing and was scored from the videotapes once every $2 \mathrm{~s}$. Defecation was defined as the total number of fecal boli present under the shuttle box (both sides) at the end of the session. The number of side crossings was defined as the number of times the rat moved from one side to the other as detected by the floor switches. The number of nose crossings was defined as the number of times any part of the rat's face (but not just the vibrissae) crossed the center divider in a direction away from the rat's body. Side preference was obtained by measuring the total time spent in the chamber where the rat was initially placed on the test day (termed throughout the report as test side). Escape latency was defined as the time it took the rat to make the first side crossing. If the rat remained in the test side for the entire session, it was assigned an escape latency of $300 \mathrm{~s}$.

Statistical analyses. The results of each measure were subjected to a one-way analysis of variance (ANOVA) followed by Newman-Keuls contrasts. Following Fanselow (1986, 1990), we supplemented the parametric analysis of freezing with a nonparametric (Kruskal-Wallis) ANOVA (and corresponding post hoc contrasts) because of the large number of zero scores. We followed a similar procedure for defecation in Experiment 1. All of these analyses were conducted by using BMDP software (Dixon, Brown, Engelman, \& Jennrich, 1990). The two-tailed critical region was .05 for all tests in the present article.

\section{Results}

The central observation of Experiment 1 was that the immediate-shock treatment yielded evidence of conditioning on five behavioral measures. These measures included freezing, defecation, side crossings, nose crossings, and escape latency.

Freezing and defecation. The top left panel of Figure 1 shows the mean freezing in each group. This measure is the percentage of samples scored as freezing regardless of where it occurred (black or white side). Groups I and D appeared to freeze more than Group N, the no-shock control group. The one-way ANOVA found a significant main effect of groups, $F(2,33)=4.01$. Newman-Keuls post hoc contrasts found that Groups I and D did not differ but that only Group D froze more than Group N. The supplemental nonparametric ANOVA and its corresponding post hoc contrasts were more sensitive. The effect of groups was significant, $H(2)=14.88$, and the post hoc contrasts, although revealing no difference between Groups D and I, showed that each froze more than Group N, Zs > 3.21.

The top right panel of Figure I shows the mean number of fecal boll (defecation score) for each group. Groups I and D defecated more than Group N. The ANOVA found a significant effect of groups, $F(2,33)=6.71$. Newman-Keuls tests found that Groups D and I did not differ but that each defecated more than Group N. The nonparametric ANOVA confirmed this. The effect of groups was significant, $H(2)=13.79$, and post hoc contrasts found that Groups I and D did not differ but that each defecated more than Group N, Zs $>3.15$.

Side and nose crossings. The middle left panel of Figure 1 shows the mean number of side crossings. There appeared to be fewer side crossings in the Groups D and I than in Group $\mathrm{N}$. There was a significant effect of groups, $F(2,33)=10.29$. Newman-Keuls contrasts found that Groups D and I, which did not differ, each had fewer side crossings than Group N. The middle right panel of Figure 1 shows the number of nose crossings. As with side crossings, there appeared to be fewer nose crossings in Groups D and I than in Group N. The oneway ANOVA revealed a significant effect of groups, $F(2,33)$
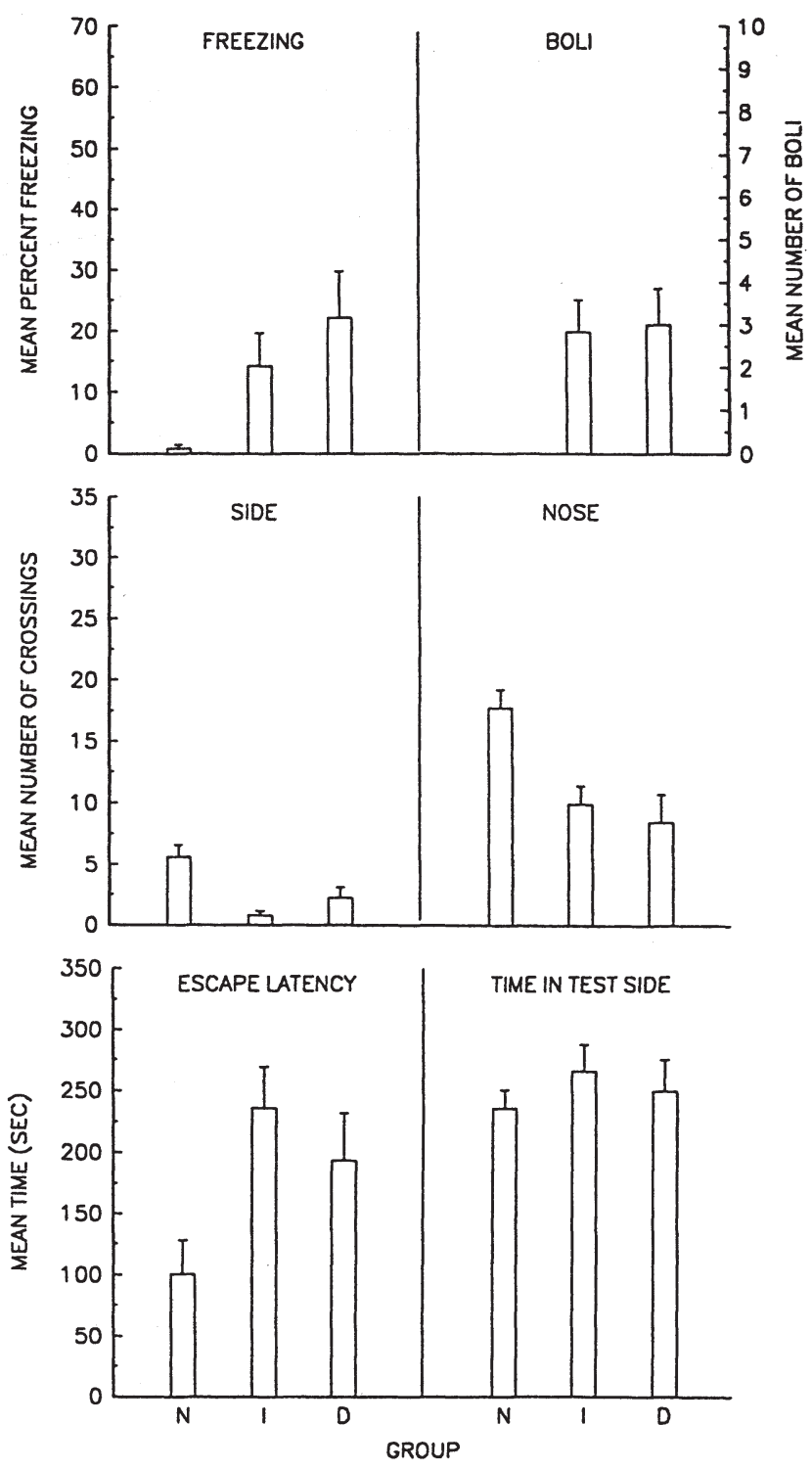

Figure 1. Results for each group in Experiment 1. Top left: mean percentage of freezing $(+S E M)$. Top right: comparable defecation results. Middle left: mean number of side crossings $(+S E M)$. Middle right: comparable nose-crossing results. Bottom left: mean time $(+S E M)$ to first leave the test box. Bottom right: mean $(+S E M)$ of total time spent in the test box (side preference). $\mathrm{N}=$ no-shock control group; I = immediateshock group; $\mathrm{D}=$ delayed-shock group. 
$=6.75$, and Newman-Keuls test found that Groups I and D, which did not differ, each had fewer nose crossings than did Group N .

Escape latency and side preference. The bottom left panel of Figure 1 shows the escape latency measure for each group. Rats in Groups I and D appeared to take longer to leave the test side (black side) than did Group N. There was a significant main effect of groups, $F(2,33)=4.29$. However, the Newman-Keuls contrasts revealed that only Group I had a longer escape latency than Group N. The bottom right panel of Figure I shows the side-preference measure (time spent on the test side). The differences among the groups were not statistically significant, $\mathrm{F}<1$.

Correlations among measures. As shown in Table 1, the side-preference measure (time in the test chamber), which was not sensitive to the independent variables, was correlated with escape latency, side crossings, and freezing. The remaining measures were significantly correlated except for the correlation between defecation and escape latency. It is reassuring that freezing, a relatively subjective measure of inactivity, was positively correlated with escape latency, an objective measure of inactivity, and was negatively correlated with two activity measures-nose crossings and side crossings-that themselves were highly and positively correlated. The sidecrossings measure, at least, was entirely objective.
Reliability of freezing and nose-crossing observations. By using the videotapes, one rater (Bevins) scored freezing and nose crossings for all the rats. A second rater (Ayres) independently scored those behaviors for 19 rats (all of those on an arbitrarily chosen reel of videotape). Neither rater knew what treatments the rats had received. The Pearson product-moment correlation between the two raters' observations was .99 for freezing and .99 for nose crossings.

\section{Experiment 2}

Experiment 2 assessed the generality of the results of Experiment 1. Experiment 2 differed procedurally from Experiment 1 in several respects: (a) Both male and female rats served as subjects, and they weighed more than those of Experiment 1; (b) in this experiment (and the remaining experiments), the rats were handled and tested by different experimenters (McPhee and Rauhut); (c) freezing and nose-crossing behaviors were scored from the videotapes by yet another experimenter (Ayres); (d) all rats received 5 min of exposure to both the black and white sides of the apparatus on each of the 2 days prior to the conditioning day; (e) on the conditioning day, the conditioning chamber was black for some rats and white for others; (f) a new control group, US-alone (Group $\mathrm{U})$, was used in addition to the no-shock control, Group N, of

Table 1

Pearson Product-Moment Correlations Among Dependent Measures in Experiments 1, 2, 3, and 4

\begin{tabular}{|c|c|c|c|c|c|}
\hline $\begin{array}{l}\text { Dependent measure } \\
\text { and experiment }\end{array}$ & Defecation & $\operatorname{Time}^{\mathrm{a}}$ & $\begin{array}{c}\text { Side } \\
\text { crossings }\end{array}$ & $\begin{array}{c}\text { Nose } \\
\text { crossings }\end{array}$ & $\%$ Freezing $^{\mathrm{b}}$ \\
\hline \multicolumn{6}{|l|}{ Escape latency } \\
\hline 1 & .30 & $.75^{* *}$ & $-.78 * *$ & $-.64 * *$ & $.50 * *$ \\
\hline 2 & $.54 * *$ & $.62 * *$ & $-.64 * *$ & $-.70 * *$ & $.64 * *$ \\
\hline 3 & -.23 & $.77 * *$ & $-.59 * *$ & $-.57 * *$ & $.64 * *$ \\
\hline 4 & $.25 *$ & $.79 * *$ & $-.62 * *$ & $-.60 * *$ & $.66^{* *}$ \\
\hline \multicolumn{6}{|l|}{ Defecation } \\
\hline 1 & - & -.04 & $-.51 * *$ & $-.63 * *$ & $.69 * *$ \\
\hline 2 & - & .12 & $-.54 * *$ & $-.62 * *$ & $.59 * *$ \\
\hline 3 & - & -.01 & $-.56 * *$ & $-.57 * *$ & $.48 * *$ \\
\hline 4 & - & .10 & $-.40 * *$ & $-.46 * *$ & $.41 * *$ \\
\hline \multicolumn{6}{|l|}{ Time $^{a}$} \\
\hline 1 & & - & $-.44 * *$ & -.29 & $.37 *$ \\
\hline 2 & & - & -.10 & -.09 & .17 \\
\hline 3 & & - & -.12 & -.22 & .28 \\
\hline \multirow{2}{*}{\multicolumn{6}{|c|}{ Side crossings }} \\
\hline & & & & & \\
\hline 1 & & & - & $.70 * *$ & $-.45^{* *}$ \\
\hline 2 & & & - & $.79 * *$ & $-.64 * *$ \\
\hline 3 & & & - & $.78 * *$ & $-.71 * *$ \\
\hline \multirow{2}{*}{\multicolumn{6}{|c|}{$\begin{array}{l}4 \\
\text { Nose crossings }\end{array}$}} \\
\hline & & & & & \\
\hline 1 & & & & - & $-.69 * *$ \\
\hline 2 & & & & - & $-.86^{* *}$ \\
\hline 3 & & & & - & $-.76^{* *}$ \\
\hline 4 & & & & - & $-.74 * *$ \\
\hline
\end{tabular}

a Time $=$ time spent in text box. ${ }^{b} \%$ freezing $=$ percentage of samples scored as freezing.

$* p<.05$. ** $p<.01$. 
Experiment 1. Rats in this group received their shock US in a (nontarget) context distinctively different from the black and white boxes. This treatment was designed to control for the nonassociative effects of shock. Arguably, the procedure used with this control group was a more conservative control procedure than the no-shock procedure used in Experiment 1 (see Bevins \& Ayres, 1995).

\section{Method}

Animals. The animals were 40 Holtzman-descended albino rats (Rattus norvegicus), 18 females and 22 males. The male rats ranged in weight from 488 to $726 \mathrm{~g}$; the female rats ranged from 281 to 464 $\mathrm{g}$. The rats were housed and maintained as before.

Apparatus. With the following minor exceptions, the two-way shuttle box remained unchanged. The litter tray for both the black and white sides was lined with gray corrugated cardboard. The switch mounted on the white side was positioned in such a way that the experimenter had to depress the switch manually to start the session there. Because the male rats were much larger than the female rats of Experiment 1, we widened the opening in the dividing wall to $10 \mathrm{~cm}$ to ensure unrestricted access to both sides of the shuttle box on the test day.

The new control group, Group U, received its shock US in a separate box located in a different room. This other box, termed Box V, was housed in a $0.61-\mathrm{m}$ cube of $12.7-\mathrm{mm}$ plywood, lined with acoustical tile. Two metal plates inserted into Box $\mathrm{V}$ as false end walls formed a truncated V. The plates were separated by $22.6 \mathrm{~cm}$ at lid level and by $4.4 \mathrm{~cm}$ at floor level. The front and back clear Plexiglas walls were $20.3 \mathrm{~cm}$ apart, and the Plexiglas lid was $19.2 \mathrm{~cm}$ from the floor. The floor between the metal plates consisted of four stainless steel rods, $2 \mathrm{~mm}$ in diameter, mounted $1.3 \mathrm{~cm}$ apart. Masking noise $(80 \mathrm{~dB})$ was provided through a speaker located on the box lid. Ambient lighting was provided by a frosted red bulb $(7.5 \mathrm{~W}, 110 \mathrm{~V})$ mounted on the rear wall of the housing cube. Shock was delivered to the grid floor and to the two inserted metal plates by the identical shock source and scrambler described previously. Sessions in Box V were started by pushing a handheld microswitch.

Procedure. Each rat was randomly assigned to one of four groups $(n \mathrm{~s}=10)$ : I, D, N, or U. By mistake, a rat assigned to Group N was given the I procedure. So the final sample sizes were 11, 10, 9, and 10 in Groups I, D, N, and U, respectively. As much as possible, groups were balanced for sex.

On Days 1 and 2, each rat was confined to either the black or white side of the shuttle box for $5 \mathrm{~min}$. Then the rat was moved immediately to the other side of the shuttle box and preexposed to that side for another $5 \mathrm{~min}$. The order of exposure was counterbalanced across rats. The aim of this preexposure was to reduce any neophobia that might be evoked by either side. Such neophobia might have discouraged rats in Groups D and I from escaping from the conditioning chamber in Experiment 1, reducing the sensitivity of the side-preference measure.

On Day 3 (conditioning day), rats in Groups I, D, and $\mathrm{N}$ received treatment in either the black or white side of the two-way shuttle box. Rats in Group U received their treatment in Box V. Rats in Groups land $U$ received a $1.0-\mathrm{mA}, 2.0$-s shock $2.5 \mathrm{~s}$ after the session was started by microswitch closure. Rats in Group D received the shock $120 \mathrm{~s}$ after microswitch closure. Rats in Group N were placed in either the white or black side and treated like Group I except that no shock was delivered. (Measurements made from the videotapes after the experiment indicated that, because of the difference in micro- switch placement between the two sides, the preshock time was about $2.6 \mathrm{~s}$ longer for rats placed in the white side than for those placed in the black side.). Rats receiving shock were removed from their conditioning chamber $30 \mathrm{~s}$ after shock termination. Each rat in Groups I, $\mathrm{D}$, and $\mathrm{N}$ was transported by hand from its home cage to the conditioning room. Each rat in Group U was placed on a metal cart while still in its home cage, which was covered with a sheet of plywood. The rat was then transported on the cart to a conditioning room separate from the other groups' conditioning room.

On Day 4 (test day), each rat in Groups I, D, and N was placed in the treatment context of the previous day. Half the rats in Group U, which had been shocked in Box V, were placed in the black side for testing; the remaining half were placed in the white side. As previously noted, the side in which they were placed was termed the test side. The solid metal divider that separated the black and white sides was replaced with the metal divider with the opening. All rats were filmed for $5 \mathrm{~min}$.

Statistical analyses. In addition to the previously described statistical procedures, we also performed preliminary Kruskal-Wallis ANOVAs followed by post hoc contrasts on all the measures to see whether there were any differences between the two control groups ( $\mathrm{N}$ and $\mathrm{U}$ ). Finding no such differences, we pooled these groups into a single combined control group in all of the other analyses.

\section{Results}

The central observation of Experiment 2 was that the immediate-shock treatment yielded evidence of conditioning on four behavioral measures. These measures included freezing, defecation, side crossings, and nose crossings.

Freezing and defecation. The two experimental groups (Groups I and D) appeared to freeze more than the two control groups (Groups U and N), which themselves showed virtually no freezing (see top left panel of Figure 2). A one-way ANOVA revealed a significant effect of groups, $F(2,37)=26.05$, and Newman-Keuls contrasts revealed that Groups I and D, which did not differ, each froze more than the combined controls. The supplemental nonparametric ANOVA confirmed this impression, $H(2)=24.76$, as did the corresponding post hoc contrasts $(\mathrm{Zs}>3.34)$.

Inspection of the top right panel of Figure 2 suggests that Groups I and D defecated more than did the two controls. Indeed, there was a significant main effect of groups, $F(2,37)$ $=15.53$. Newman-Keuls contrasts showed more defecation in both Groups I and D than in the combined controls.

Side and nose crossings. There appeared to be fewer side crossings in the experimental groups than in the controls (see Figure 2, middle left panel). A one-way ANOVA revealed a significant effect of groups, $F(2,37)=10.32$, and NewmanKeuls contrasts showed that Groups D and I, which did not differ, each had fewer side crossings than the combined controls. The middle right panel of Figure 2 shows the number of nose crossings. There was a significant main effect of groups, $F(2,37)=13.99$, and Newman-Keuls tests revealed that Groups I and D, which did not differ, each had fewer nose crossings than did the combined controls.

Escape latency and side preference. The bottom left panel of Figure 2 shows the escape latency measure. The es- 
cape latencies in Groups I and D appeared longer than in the controls. A one-way ANOVA revealed a significant effect of groups, $F(2,37)=4.91$. However, Newman-Keuls contrasts demonstrated that only group D had longer escape latencies than the combined controls. Groups land D did not differ. The bottom right panel of Figure 2 shows the side-preference measure (time spent in the test side, which for Groups land D was the conditioning side). Differences among groups were small, and a one-way ANOVA revealed no significant effect $(F<1)$.
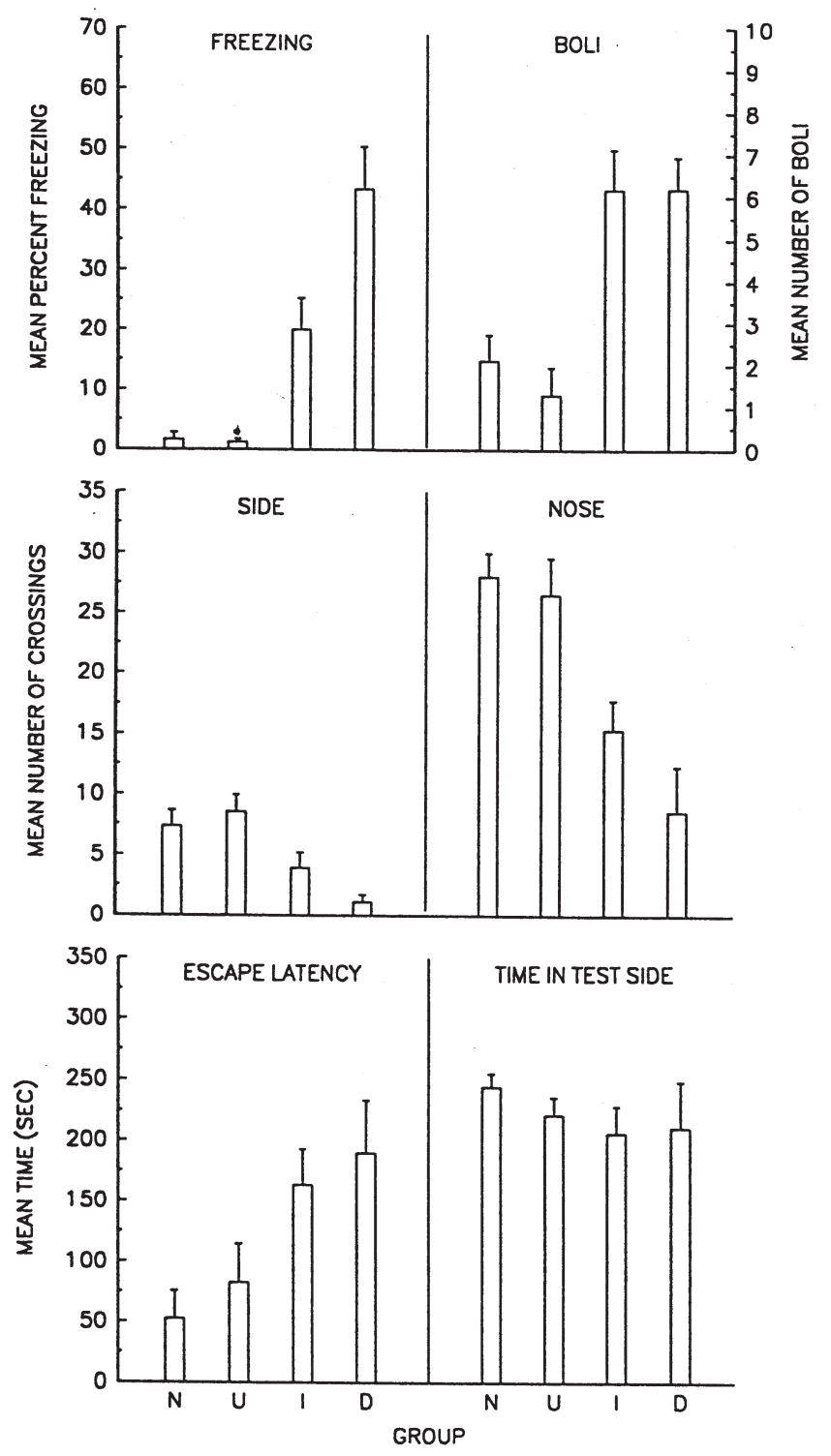

Figure 2. Results for each group in Experiment 2. Top left: mean percentage of freezing $(+S E M)$. Top right: comparable defecation results. Middle left: mean number of side crossings (+SEM). Middle right: comparable nose-crossing results. Bottom left: mean time $(+S E M)$ to first leave the test box. Bottom right: mean $(+S E M)$ of total time spent in the test box (side preference). $\mathrm{N}=$ no-shock control group; $\mathrm{U}=$ unconditioned stimulus (US) alone control group; I = immediate-shock group; $\mathrm{D}=$ delayed-shock group.
Contrary to our previous suggestion, context preexposure did not boost the sensitivity of this measure.

Supplemental analyses. To see whether the brightness of the test side (black vs. white) was an important factor, we performed Groups $\times$ Brightness parametric ANOVAs on each of the dependent variables. None of these ANOVAs revealed a significant main effect of brightness or an interaction of brightness with groups. To see whether sex of the rats was an important factor, we performed Groups $\times$ Sex ANOVAs on each dependent variable. These analyses revealed that males froze more, defecated more, and had longer escape latencies than did females. Sex, however, did not interact with the groups factor. (Note: we chose not to perform a Groups $\times$ Brightness $\times$ Sex ANOVA because of the small and unequal sample sizes in the resultant cells of the $3 \times 2 \times 2$ table.)

Correlations among measures. As shown in Table I, the side-preference measure (time in the test chamber), which was not sensitive to the independent variables, correlated only with escape latency. The remaining measures were highly correlated $(p s<.01)$.

Reliability of freezing and nose-crossing observations. By using the videotapes, one rater (Ayres) scored freezing and nose crossings for all the rats. A second rater (McPhee), trained to score freezing at another university, independently scored those behaviors for a subset of 18 rats (all of those on an arbitrarily chosen reel of videotape). Neither rater knew what treatments the rats had received. The Pearson productmoment correlation between the two raters' observations was .91 for freezing and .99 for nose crossings.

\section{Experiment 3}

Under different procedures, Experiments 1 and 2 established that an immediate shock can impart associative value to contextual cues. Evidence for conditioned fear was found in four of the six dependent measures: freezing, defecation, side crossings and nose crossings. Experiment 3 further assessed the generality of these effects. It combined the counterbalancing procedures of Experiment 2 (i.e., conditioning side and sex) with the absence of box preexposure (as in Experiment 1). The preexposure to the black and white sides was eliminated because it did not enhance the sensitivity of the side-preference measure in Experiment 2. Most importantly, in Experiment 3, we reduced the shock intensity from 1.0 to $0.5 \mathrm{~mA}$. Weaker shock might produce a data pattern more like that obtained in Fanselow's laboratory (Fanselow, 1986, 1990) and less like that found in our laboratory (Bevins \& Ayres, 1994, 1995). If so, then that result would be consistent with the suggestion that a difference in shock effectiveness between the two laboratories might explain the discrepant effects of immediate shock found in those laboratories.

\section{Method}

Animals. The animals were 36 Holtzman-descended albino rats (Rattus norvegicus), 18 females and 18 males. Male rats ranged in 
weight from 357 to $623 \mathrm{~g}$; female rats ranged from 249 to $384 \mathrm{~g}$. The rats were housed and maintained as before.

Apparatus. The apparatus was unchanged except that the microswitch for the white side was positioned such that placement of a rat into that chamber triggered the session. This change ensured that the time between placement and shock would be identical for rats conditioned in either the black or the white side.

Procedure. Rats were randomly assigned to the cells of a $3 \times 2 \times$ 2 design in which the factors were treatment (I, D, and U), brightness of the test box (black or white), and sex. Three rats were assigned to each cell. On Day 1, the rats received their experimental treatment. On Day 2, the six dependent measures were recorded in the two-way shuttle box. Half the rats in Group U were placed singly in the black side; half were placed singly in the white side. Rats in Groups I and $\mathrm{D}$ were placed in the box where they had received shock on Day 1 (i.e., the test side). Except for the use of a $0.5-\mathrm{mA}$ scrambled grid shock and the change in position of the white floor switch, all other aspects of the conditioning and testing procedures were the same as those in Experiment 2.

\section{Results}

The central observation of Experiment 3 was that only the delayed-shock treatment and not the immediate-shock treatment yielded evidence of conditioning. The immediate-shock deficit was complete.

Freezing and defecation. Inspection of the top left panel of Figure 3 suggests that only Group D froze more than the control group (Group U). A one-way ANOVA found a significant effect of groups, $F(2,33)=47.12$, and Newman-Keuls contrasts found that Group D froze more than Groups I and U, which did not differ. The supplemental nonparametric ANOVA confirmed this, $H(2)=19.92$, as did the corresponding post hoc contrasts, $\mathrm{Zs}>3.42$.

Group D defecated more than Group U, whereas Group I defecated at an intermediate level (see top right panel of Figure 3). The one-way ANOVA found a significant effect of groups, $F(2,33)=14.60$, and Newman-Keuls contrasts showed more defecation in Group D than in Groups land U, which did not differ.

Side and nose crossings. The middle left panel of Figure 3 shows the mean number of side crossings. Group D appeared to cross from side to side less often than Groups I and U. An ANOVA found a significant effect of groups, $F(2,33)=17.79$, and Newman-Keuls contrasts revealed that Group D did indeed cross less often than Groups land U, which did not differ. The middle right panel of Figure 3 shows the number of nose crossings. Group D appeared to have fewer nose crossings than Groups I and U. An ANOVA found a significant effect of groups $F(2,33)=17.32$, and Newman-Keuls tests found that Group D had fewer nose crossings than Groups I and U, which again did not differ.

Escape latency and side preference. The bottom left panel of Figure 3 shows the escape latency measure. Escape latencies in Group D appeared longer than those for Group I; Group U's mean latency appeared intermediate. A oneway ANOVA found a significant effect of groups, $F(2,33)=$ 6.16 , and Newman-Keuls contrasts found the mean latency
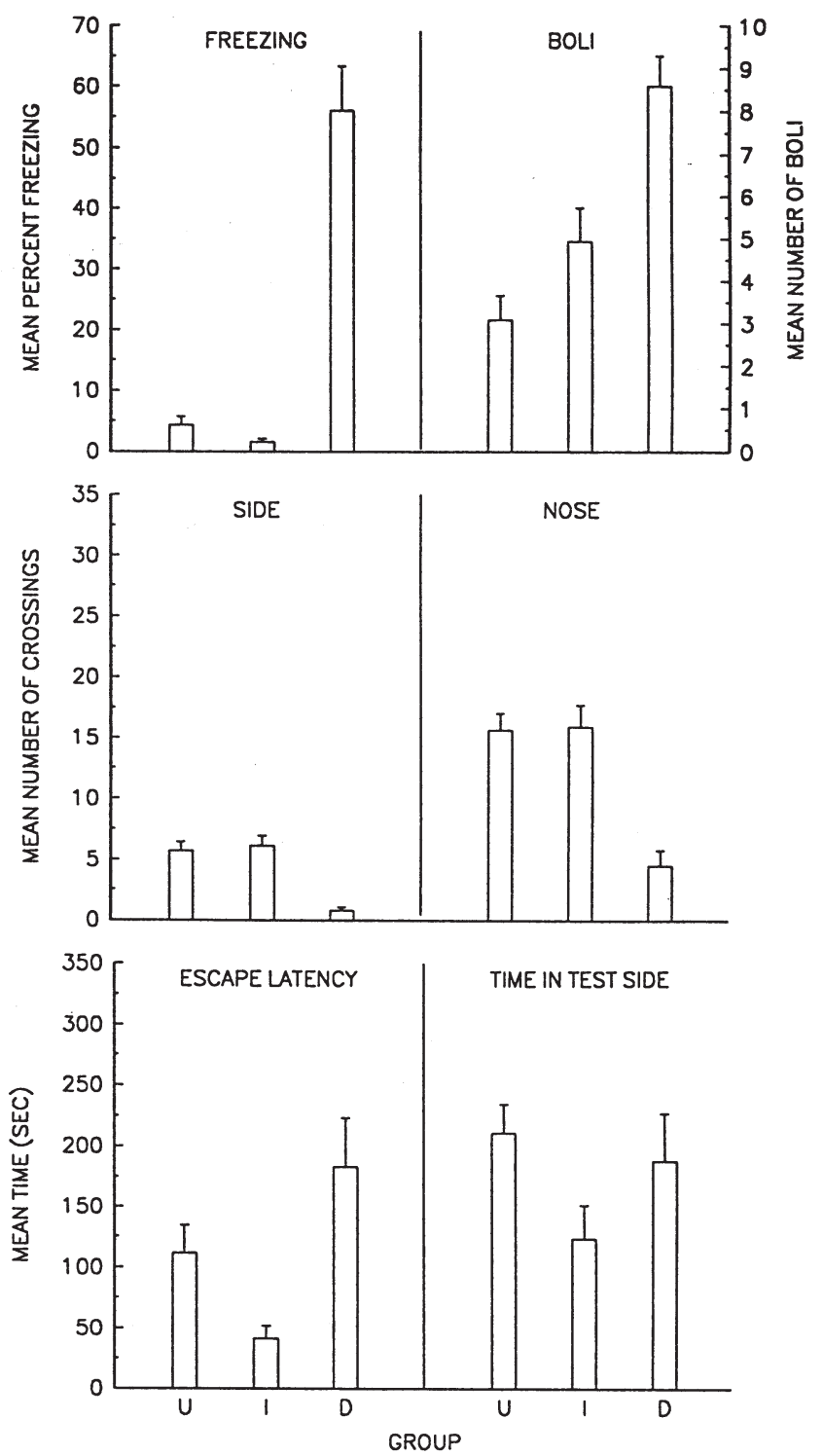

Figure 3. Results for each group in Experiment 3. Top left: mean percentage of freezing $(+S E M)$. Top right: comparable defecation results. Middle left: mean number of side crossings ( $+S E M)$. Middle right: comparable nose-crossing results. Bottom left: mean time $(+S E M)$ to first leave the test box. Bottom right: mean $(+S E M)$ of total time spent in the test box (side preference). $\mathrm{U}=$ unconditioned stimulus (US) alone controlgroup; I = immediate-shock group; $\mathrm{D}=$ delayed-shock group.

to be longer in Group D than in Group I. Group U did not differ from either Group D or Group I. The bottom right panel of Figure 3 shows the side-preference measure (time spent in the test side). As in Experiments 1 and 2, differences among groups were small, and the one-way ANOVA found no effect of groups, $F(2,33)=2.02, p>15$.

Supplemental analyses. To see if brightness of the test side and sex of the rat were important factors, we performed Groups $\times$ Brightness $\times$ Sex parametric ANOVAs on each dependent variable. (Note: In contrast to our choice in Experiment 2, we chose here to use a Groups $\times$ Brightness $\times$ Sex 
ANOVA because the sample sizes in the $3 \times 2 \times 2$ table, though still small, were at least equal, $n \mathrm{~s}=3$ ). These analyses revealed that males had longer escape latencies and made fewer side crossings than did females. In addition, rats spent more time in the test side when it was black than when it was white. Neither brightness of the test side nor sex interacted with any other factor with one exception: for the side-crossing measure, brightness interacted with group. Inspection of the means for each brightness in each group did not suggest a meaningful interpretation of this interaction.

Correlations among measures. As shown in Table 1, the correlations among measures were similar to those obtained in Experiment 2 with one exception: Here, the correlation between defecation and escape latency was not significant.

Reliability of freezing and nose-crossing observations. By using the videotapes, one rater (Ayres) scored freezing and nose crossings for all the rats. A second rater (McPhee ) independently scored those behaviors for a subset of 20 rats (all of those on an arbitrarily chosen reel of videotape). Neither rater knew what treatments the rats had received. The Pearson product-moment correlation between the two raters' observations was .98 for freezing and .99 for nose crossings.

\section{Experiment 4}

Bevins and Ayres (1995) suggested that shock effectiveness could be an important determinant of contextual conditioning with immediate shock. The lack of evidence of such conditioning in Experiment 3 with a $0.5-\mathrm{mA}$ shock, coupled with the evidence for such conditioning in Experiments land 2 with a $1.0-\mathrm{mA}$ shock, is consistent with their suggestion. Experiment 3, however, also differed procedurally from Experiments 1 and 2 in ways other than shock intensity. Experiment 4 , therefore, directly compared the two intensities $(0.5$ and 1.0 $\mathrm{mA}$ ). Although we felt it unnecessary to include a delayedshock group, we knew that it would show good conditioning at both intensities, and so we included that group for completeness and to provide a benchmark. The design was thus a $3 \times 2 \times 2 \times 2$ factorial, in which the factors were treatment (I, $\mathrm{D}$, or U), US intensity, brightness of the test box, and sex.

\section{Method}

Animals and apparatus. The animals were 96 Holtzman-descended albino rats (Rattus norvegicus), 48 females and 48 males. The male rats ranged in weight from 451 to $720 \mathrm{~g}$; the female rats ranged from 247 to $399 \mathrm{~g}$. The rats were housed and maintained as before. The apparatus was unchanged from Experiment 3.

Procedure. Rats were randomly assigned to the cells of a $3 \times 2 \times$ $2 \times 2$ design in which the factors were treatment $(1, \mathrm{D}$, or $\mathrm{U})$, shock intensity ( 0.5 or $1.0 \mathrm{~mA}$ ), brightness of the test box (black or white), and sex. Four rats were assigned to each cell. On Day 1, the rats received their experimental treatment. For half the rats in each group, the shock intensity was $0.5 \mathrm{~mA}$; for the remaining rats, it was 1.0 $\mathrm{mA}$. All other aspects of the procedure, including counterbalancing, handling, and transporting, were as described in Experiment 3. On Day 2, the six dependent measures were recorded in the two-way shuttle box. Half the rats in Group U were placed singly in the black side; half were placed singly in the white side. Rats in Groups land D were placed in the chamber where they had received shock on Day 1 (i.e., the test side).

Statistical analysis. Because our hypothesis was that, relative to Group U, Group I would show evidence for conditioning with the 1.0$\mathrm{mA}$ shock but not with the $0.5-\mathrm{mA}$. shock, our statistical tests focused on that hypothesis. Thus, for each measure, we subjected the data for Groups land U to a Groups $\times$ US Intensity $\times$ Brightness $\times$ Sex ANOVA to generate an overall error term to be used in two planned (-test comparisons. One test compared $\sim$ Group I with Group U under the 0.5-mA shock condition. Here we expected no difference among groups. The second test compared Group I with Group U under the 1.0-mA shock condition. Here we expected more freezing, more defecation, fewer side crossings, and fewer nose crossings in Group I than in Group U. For the freezing measure, we supplemented the $t$ tests with their nonparametric counterparts (Mann-Whitney $U$ tests).

\section{Results}

The central observation of Experiment 4 was that the immediate, strong-shock treatment $(1.0 \mathrm{~mA})$ yielded evidence of contextual conditioning according to four measures: freezing, defecation, side crossings, and nose crossings. Immediate, weak-shock treatment $(0.5 \mathrm{~mA})$, however, yielded evidence for conditioning according to only the defecation measure.

Freezing and defecation. The top left panel of Figure 4 shows the freezing for each group. Group I froze more than the control group (Group U) only at the 1.0 -mA shock intensity. The $t$-test and $U$-test comparisons found no difference between Groups I and $U$ at the $0.5-\mathrm{mA}$ intensity, $t(30)$ $<1.00, U=141.0$; but, at the $1.0-\mathrm{mA}$ intensity, there was significantly more freezing in Group I than in Group $\mathrm{U}, t(30)$ $=2.14, U=181.5$. Group I appeared to defecate more than Group U under both US intensities (see top right panel of Figure 4). The $t$-test comparisons supported that impression. At the $0.5-\mathrm{mA}$ shock, $t(30)=2.47$; at the $1.0-\mathrm{mA}$ shock, $t(30)=1.90, p<.05$, one-tailed.

Side and nose crossings. The middle left panel of Figure 4 shows the mean number of side crossings for each group. There appeared to be fewer side crossings in Group I than in Group U only under the 1.0-mA shock. The $t$-test comparisons confirmed that impression. There was no difference between Groups I and U under the $0.5-\mathrm{mA}$ shock, $t(30)=1.01$. However, Group I made fewer side crossings than did Group $U$ at the $1.0-\mathrm{mA}$ level, $t(30)=3.50$. The middle right panel of Figure 4 shows the mean number of nose crossings. The figure suggests fewer nose crossings in Group I than in Group U only under the $1.0-\mathrm{mA}$ shock. The $t$-test comparisons found no difference between groups under the 0.5 -mA shock, $t(30)<1.00$, but found that Group I made fewer nose crossings than Group $\mathrm{U}$ under the $1.0-\mathrm{mA}$ shock, $t(30)=3.13$.

Escape latency and side preference. The bottom left panel of Figure 4 shows the escape latency measure; the bottom right panel shows the side-preference measure. Group I did not differ from Group U on either measure at either shock level, largest $t(30)=1.11$. 

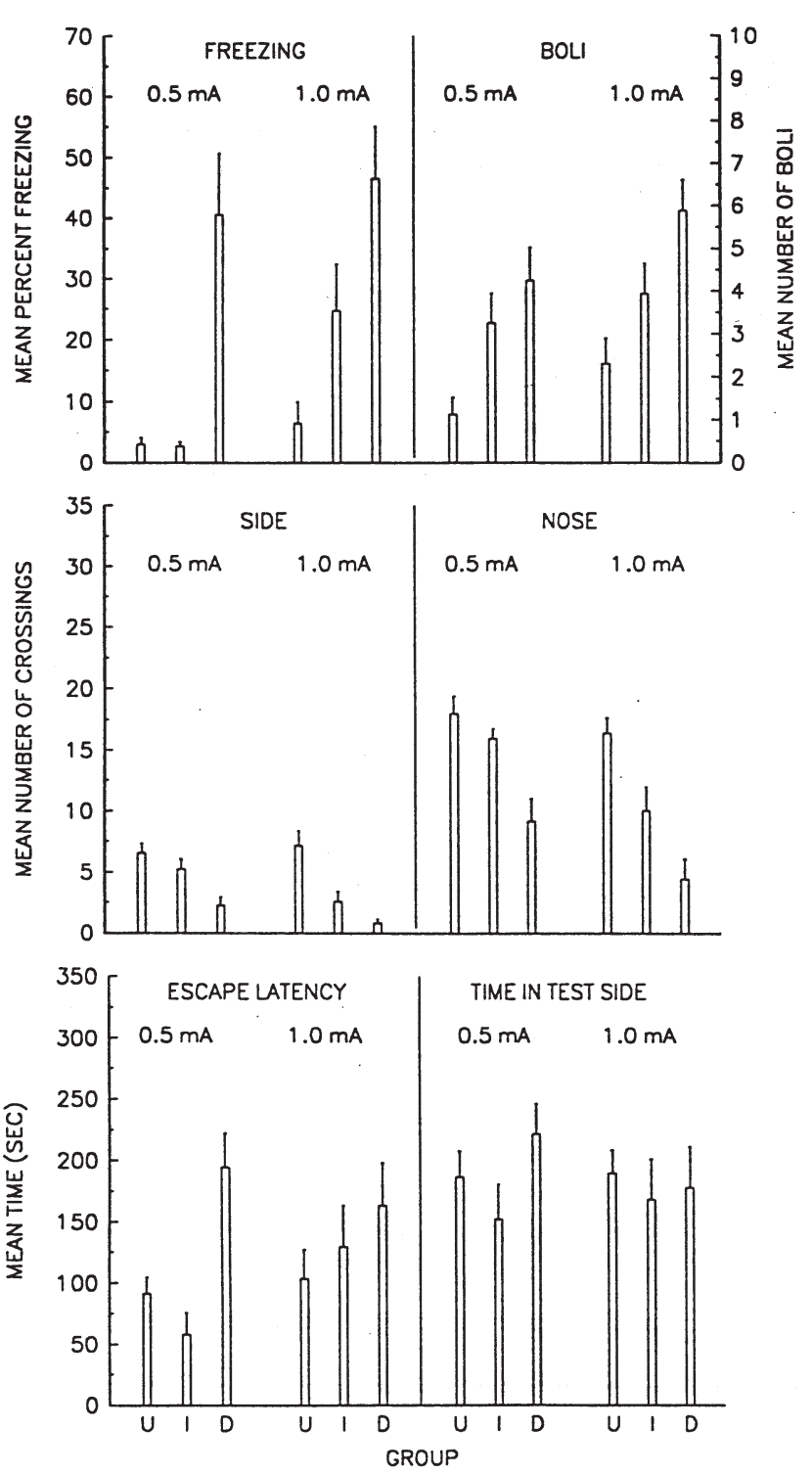

Figure 4. Results for each group in Experiment 4. Top left: mean percentage of freezing $(+S E M)$. Top right: comparable defecation results. Middle left: mean number of side crossings $(+S E M)$. Middle right: comparable nose-crossing results. Bottom left: mean time $(+S E M)$ to first leave the test box. Bottom right: mean $(+S E M)$ of total time spent in the test box (side preference). $\mathrm{U}=$ unconditioned stimulus (US) alone control group; I = immediate-shock group; $\mathrm{D}=$ delayed-shock group.

Supplemental analyses. To see if brightness of the test box and sex were important factors, we performed Groups $\times$ us Intensity $\times$ Brightness $\times$ Sex parametric ANOVAs on each dependent variable, using the data of all three groups (including Group D). For the defecation measure, a significant interaction was found between groups and sex. Inspection of the means revealed that male rats tended to defecate more than female rats in Groups I and U but not in Group D. For the sidepreference measure, a main effect of brightness indicated that rats spent more time in the test side when it was black than when it was white. For the side-crossing measure, there was a significant three-way interaction between groups, US intensity, and sex. That interaction appeared to reflect the fact that side crossings tended to decrease as shock intensity increased, except for male rats in Group U. For the nose-crossing measure, there was a significant four-way interaction (Groups $\times$ US Intensity $\times$ Brightness $\times$ Sex). That interaction is complex and probably reflects only the small sample sizes in the cells of the four-way table.

Correlations among measures. As shown in Table 1, the correlations among measures were similar to those in the previous experiments. Exceptions occurred only where correlations in the earlier experiments were inconsistent. For example, the correlation between defecation and escape latency was significant, as it was in Experiment 2 but not in Experiments 1 and 3. Also, time in the test chamber was negatively correlated with side and nose crossings and was positively correlated with freezing. In Experiments 2 and 3, these correlations were in the same direction but were not significant. In Experiment 1, as in Experiment 4, the side-crossing and freezing measures were significantly correlated with time in test side. However, the correlation with nose crossings was not significant in Experiment 1.

Reliability of freezing and nose-crossing observations. By using the videotapes, one rater (Ayres) scored freezing and nose crossings for all the rats. A second rater (Wynn) independently scored those behaviors for 48 rats. A third rater (McPhee) independently scored those behaviors for another 24 rats. Thus, 72 of the 96 rats were independently scored by two raters. No rater knew what treatments the rats had received. The Pearson product-moment correlation between the 72 pairs of independent observations was .99 for freezing and .96 for nose crossings.

\section{General Discussion}

To date, this report provides the strongest evidence that immediate shock can effectively condition contextual cues. Our freezing, defecation, side-crossing, and nose-crossing measures all revealed evidence for context conditioning with the 1.0-mA immediate shock in Experiments 1, 2, and 4. This evidence should minimize concerns that subtle differences between laboratories in the technique of scoring freezing may explain the discrepant reports of immediate-shock conditioning. Indeed, even the completely objective measure of side crossings revealed evidence of context conditioning in Experiments 1,2 , and 4 , in which the $1.0-\mathrm{mA}$ shock was used. Moreover, the ratings by an observer (McPhee) trained to score freezing at another university correlated highly with ratings made by observers from the University of Massachusetts at Amherst (see Experiments 2 and 3). This evidence that immediate shock can support conditioning to contextual cues suggests that theories of contextual conditioning must contain mechanisms that permit such conditioning to occur. One such theory has recently been proposed (Bevins \& Ayres, 1995; see also McLaren, Kaye, \& Mackintosh, 1989). 
The theory offered by Bevins and Ayres (1995) is a stimulus sampling theory (Estes, 1950). It assumes that the context comprises many elements. It further assumes that the rat can sample only a small subset of these elements prior to immediate shock. That small subset will then acquire conditioned value. The value acquired will increase with us intensity. When the animal is tested at a later date, the context will be unlikely to evoke a conditioned response because the rat is unlikely to sample the identical subset of elements that was previously sampled prior to shock. According to this view, however, the immediate-shock deficit need not be complete. In the test period, conditioned responding will increase with the fraction of the elements in the sample that are conditioned. Any factor that promotes the sampling of the same elements on the test trial as on the conditioning trial will increase the odds of detecting a conditioned response. Any factor that reduces conditioning to the sampled elements (such as a weak shock intensity) or promotes the sampling of new elements on the test trial will reduce the odds of detecting a conditioned response. Detection of conditioned responding is highly likely following delayed shock because the rat has a chance to sample more of the stimulus elements prior to US onset. Assuming that this sampling has occurred in reasonable temporal contiguity to shock, all of these elements stand to gain conditioned value. If a large fraction of the available elements is then conditioned, a conditioned response on the occasion of testing becomes highly likely because almost any sample at any moment will contain a high proportion of conditioned elements.

Among the elements that stand to be conditioned by immediate shock are transportation cues and box placement cues. By transportation cues, we mean those cues specific to transporting the rat from the colony to the conditioning or test room. By box placement cues, we refer to the manner in which the rat is held when it is placed in the box and to the rat's exact location in the box when first placed there. Because these cues tend to be associated with the start of a session, they are likely to be conditioned by immediate shock and to evoke freezing in the test session only early in that session. These cues are less likely to have been recently sampled prior to delayed shock because their traces should weaken over time. The cues that are sampled prior to delayed shock are those cues that tend to be present throughout the session. The result would be that freezing in the test session should be more broadly distributed and not confined to the start of the session. Thus, immediate and delayed shocks should produce different distributions of freezing suggestive of (but not demanding the concept of) $\mathrm{v}$ timing (timing which is less accurate when shock is delayed than when it is immediate). Bevins and Ayres (1995) found distributions of freezing consistent with these expectations.

Although we feel that the present evidence for conditioning with immediate shock is strong, we anticipate criticisms of our measures and wish to rebut them.

First, for each rat, our freezing and defecation measures describe the total freezing and defecation that occurred, regard- less of whether it occurred in the conditioned chamber, the nonconditioned chamber, or in some combination of the two. These two measures might thus be criticized as being uninterpretable in that they do not reveal exactly where the crucial behavior occurred. Here, we wish to note the following: (a) The main issue in this research is whether contextual conditioning can result from immediate shock. Freezing and defecation are widely accepted as measures of context fear (e.g., Fanselow, 1986, 1990). Freezing and defecation are not expected to be evoked by nonconditioned contexts, and this expectation is borne out by the lack of freezing in Groups $\mathrm{N}$ and $\mathrm{U}$ for which neither context was conditioned. Allowing a rat that has received shock in a target context to leave that context and spend part of its time in a nonconditioned context (or a context to which fear has not completely generalized) should thus produce less freezing and defecation than would occur if the rat were confined to the target context. In terms of our measures of freezing and defecation, a conditioned rat with access to two contexts should thus resemble a control rat more than should a conditioned rat confined to the target context. Our procedure of totaling the freezing and defecation regardless of where the rat spent its time is therefore biased against finding more freezing and defecation in an immediate-shock group than in a control group. (b) In none of our experiments was there any evidence that groups differed in the amounts of time they spent in the conditioned context. So however the availability of two contexts may have complicated our measures, that availability did not seem to affect the groups differentially. (c) The primary criterion for evaluating any dependent variable should be its sensitivity to the independent variable. Our freezing and defecation measures were quite sensitive. As expected from previous reports (e.g., Fanselow, 1986, 1990), they showed clear evidence for context fear conditioning in our groups that received delayed shock. They also showed evidence for conditioning in our groups that received immediate shock (at $1.0 \mathrm{~mA}$ ), a finding consistent with some previous reports (Bevins \& Ayres, 1994, 1995; Blanchard et al., 1976) but not others (e.g., Fanselow, 1986, 1990). (d) A secondary criterion for evaluating a dependent measure is its consistency with other measures. Our freezing and defecation measures were positively correlated with each other, and both were negatively correlated with other measures of movement (nose crossings and side crossings). In the wild, movement is known to trigger predatory attack (Fox, 1969; Kaufman, 1974; Van Hemel \& Colucci, 1973). The frightened rat, therefore, is expected to reduce its movement. The most extreme reduction (in a nonrestrained rat) is freezing. The fact that our freezing and defecation measures were negatively correlated with the other measures of movement thus makes sense in terms of the functional significance of movement reduction in the frightened rat and highlights the consistency of these measures.

Second, our escape latency measure might be criticized for failing to show faster escape from the test chamber in rats presumably most afraid of it. In truth, initially we expected the more frightened rats to escape faster, but in retrospect this 
expectation was unrealistic. The dominant reaction of the rat to a feared context is freezing (Fanselow \& Lester, 1988), even when the rat has been given ample time to learn that escape routes are available. When escape speeds are used to measure context fear, those speeds are often very slow at first, and they reach their maximum only after about 50 escapes (McAllister, McAllister, Scoles, \& Hampton, 1986). Our frightened rats failed to escape rapidly because they were freezing. In all of our experiments, freezing and escape latency were highly correlated.

Third, our side-preference measure might be criticized for failing to show a greater preference for the nonconditioned side in our experimental (frightened) rats than in our control rats. Again, this failure reflects the freezing that occurred in the conditioned side. Rats who froze more in the conditioned context tended to spend more time there, presumably because the freezing increased the escape latencies. Thus, freezing distorts the measure of side preference.

The present evidence for immediate-shock conditioning revives the question as to why our laboratory finds immediate shock to be effective in this and other studies (Bevins \& Ayres, 1995), whereas Fanselow and colleagues do not (Fanselow, 1990; Fanselow et al., 1994). Bevins and Ayres (1995) suggested that the Hoffman-Fleshler shock scramblers, used in their own work and in the present study, delivered a more potent 2-s, 1.0-mA shock than the Grason-Stadler scramblers used by Fanselow. That suggestion received indirect support here: When we used a $0.5-\mathrm{mA}$ shock US, we replicated the (complete) immediate-shock freezing deficit described by Fanselow (1986, 1990); however, when we used a 1.0-mA shock, we consistently found evidence on several measures for context conditioning with immediate shock-a result like that of Bevins and Ayres's studies (1994, 1995).

Unfortunately, shock effectiveness seems to be only part of the explanation. A recent study by Fanselow et al. (1995; see also Fanselow, Landeira-Fernandez, DeCola, \& Kim, 1994, p. 75) found no context-evoked freezing with a 3-s, 2.0-mA immediate shock after three conditioning trials. Although the procedural details of that study were not identical to previous work in the area (e.g., 3-min postshock time period), the lack of context conditioning with the increase in number of shock exposures, intensity, and duration suggests that factors besides shock potency determine the detection of context conditioning following immediate shock.

Two other factors possibly important for detecting such conditioning were suggested by Bevins and Ayres (1995). Both of these suggestions rest on the assumption that stimuli experienced during handling, transport, and placement into the conditioning environment are conditionable aspects of the context. Because these cues stand in good temporal relation with the immediate shock, they can acquire associative value. However, Fanselow's $(1986,1990)$ experimental protocol included handling and preexposure of the transport cues up to 10 times before the conditioning phase. In contrast, we handled our rats extensively but never transported them to the conditioning room prior to the Conditioning phase (i.e., the present article; Bevins \& Ayres, 1995). Because transport cues are very likely to be sampled just prior to immediate shock and again at the start of the test session, any procedure that retards conditioning to those cues (i.e., stimulus preexposure; Lubow, 1989) would weaken the conditionability of contextual elements by the immediate shock. This difference in preexposure, then, might lead to a complete immediate-shock freezing deficit in Fanselow's $(1986,1990)$ laboratory but to only a partial deficit in ours (i.e., the present article; Bevins \& Ayres, 1995).

A second suggestion is that transport and placement cues may be more consistent across days in our laboratory (i.e., the present article; Bevins \& Ayres, 1995) than in Fanselow's (1986, 1990). In the present study, we made great efforts to ensure that those cues were as similar as possible for every rat on both the conditioning and test day. This consistency makes it likely that the rat would sample on the test day the same cues that occurred just prior to the immediate shock on the conditioning day. Sampling of these conditioned cues on the test day would make a conditioned response likely. If transport and box placement cues were less consistent across the conditioning and test days in Fanselow's laboratory, then this would decrease the odds of detecting conditioning with the immediate shock.

There are results from laboratories other than Fanselow's that appear to dispute our conclusion that immediate shock can support contextual conditioning. We believe that careful study of these results will reveal that they are not necessarily inconsistent with our view. For example, Kieman et al. (1995) described several measures of conditioning that suggested that the immediate-shock deficit was complete. However, from our theoretical view, their measures were not ideal for detecting conditioning following immediate shock. One of their measures was postshock freezing during the conditioning session. We believe that measure is likely to be insensitive because shock necessarily alters the rat's posture and orientation and prompts the rat to sample cues other than those sampled prior to shock onset. Moreover, during the postshock activity burst, the traces of handling, transport, and box placement should begin to fade. It is true that Blanchard et al. (1976) did find some evidence in a postshock test for some conditioning following immediate shock, but they used a 3.0-mA shock. That shock would have been very effective in conditioning whatever elements preceded shock onset and happened to be sampled again postshock. A second measure used by Kieman et al. was step-down latency. Rats that received immediate shock were later found to be similar to control rats in their latencies to step down from a platform placed in the conditioning chamber. This task, we feel, is also likely to be insensitive because it alters the box placement cues that preceded the immediate shock. On the conditioning day, there was no step-down platform, and the rat was not placed on one. A third measure used by Kiernan et al. was fear-potentiated startle. Here, 80 auditory startle stimuli were presented $30 \mathrm{~s}$ apart following either immediate or delayed shock. The finding was that rats that had received immediate shock startled no more than rats that had 
received no shock. That result suggests that immediate shock failed to condition context fear. However, once again, the test was a postshock test. Moreover, in the test period, the startle stimuli would tend to prevent the rat from sampling elements that had preceded the immediate shock.

In other work that used testing procedures more like ours and those of Bevins and Ayres (1994, 1995), there is some agreement in the data. For example, Kieman and Westbrook (1993) found that rats shocked $3.0 \mathrm{~s}$ after context placement froze on slightly more than $15 \%$ of the samples taken in a subsequent test session (see their Figure 1, Test 2). That value of $15 \%$ is similar to the values reported here and by Bevins and Ayres (1995) when rats were shocked $2.5 \mathrm{~s}$ after box placement.

Regardless of the similarities and differences in the results from different laboratories, our findings suggest that immediate shock can condition context fear. This point is better established here than previously (Bevins \& Ayres, 1994, 1995) because of the consistency in the present work of so many behavioral measures of context conditioning: freezing, nose crossings, side crossings, and defecation. Though this consistency is reassuring, it is not particularly surprising because freezing, nose crossings, and side crossings are all measures of activity or its absence. Defecation, however, can occur whether the rat is active or not, and its consistent correlation with freezing is therefore more interesting. It has long been recognized that defecation is a valid measure of conditioned fear and is closely related to freezing (Hunt \& Otis, 1953). This close relationship (see also Figure 2 in Fanselow, 1986) is noteworthy given recent writings about the functional significance of a variety of behaviors motivated or organized by fear (e.g., Fanselow, 1984; Gallup, 1977). Prominent among these behaviors are freezing, fleeing, fear-potentiated startle, conditioned analgesia, and tonic immobility. A strong case has been made that these behaviors all function as antipredator behaviors. Little has been said by these researchers, however, about the possible role of defecation as an antipredator response. Because defecation is significantly correlated with freezing, one wonders if defecation might also be an antipredator behavior. Besides the possibility that urine and feces might make a prey item less palatable to a predator, there is also a possibility that they could contain substances that would provoke all alarm reaction or flight among related conspecifics. So even if the prey were itself killed, the genetically determined tendency to urinate and defecate in response to fear could be propagated through kin selection, provided that related individuals were to avoid the area of attack and hence avoid the predator (cf. Brown, Chivers, \& Smith, 1995). Giving some plausibility to this idea in rats, Muller-Velten (1966) reported that the house mouse (Mus musculus L.) showed a flight reaction to the odor of frightened conspecifics. He found that the odor was "taken up by the surroundings with which the animal comes into contact, and remains, under experimental conditions, for a period of at least 7 to 8 hours" (Muller-Velten, 1966, p. 425). It is also known that both mice and rats can discriminate the odors of stressed versus nonstressed conspecifics (Carr, Martora- no, \& Krames, 1970; Runyon, 1954; Valenta \& Rigby, 1968). Moreover, Runyon (1954) showed that rats trained to escape or avoid shock by jumping out of a chamber will jump out of a dissimilar chamber faster when it contains the odor of a shocked rat than when it does not contain this odor. He also showed that, in a Y maze, rats prefer an end box containing no odor to one containing the odor of shocked rats. Runyon's findings are consistent with the possibility that rats, like mice, avoid the odor of frightened conspecifics.

\section{References}

Bevins, R. A., \& Ayres, J. J. B. (1994). A deficit in one-trial context fear conditioning is not due to opioid analgesia. Pharmacology Biochemistry and Behavior, 49, 183-186.

Bevins, R. A., \& Ayres, J. J. B. (1995). One-trial context fear conditioning as a function of the interstimulus interval. Animal Learning \& Behavior, 23, 400-410.

Blanchard, R. J., Fukunaga, K. K., \& Blanchard, D. C. (1976). Environmental control of defensive reactions to footshock. Bulletin of the Psychonomic Society, 8, 129-130.

Brown, G. E., Chivers, D. P., \& Smith, R. J. F. (1995). Localized defecation by pike: A response to labelling by cyprinid alarm pheromone? Behavioral Ecology and Sociobiology, 36, 105-110.

Carr, W. J., Martorano, R. D., \& Krames, L. (1970). Responses of mice to odors associated with stress. Journal of Comparative and Physiological Psychology, 71, 223-228.

Dixon, W. J., Brown, M. B., Engelman, L., \& Jennrich, R. I. (Eds.). (1990). BMDP statistical software manual, vol. 1. Berkeley, CA: University of California Press.

Estes, W. K. (1950). Toward a statistical theory of learning. Psychological Review, 57, 94-107.

Fanselow, M. S. (1984). What is conditioned fear? Trends in Neurosciences, 7, 460-462.

Fanselow, M. S. (1986). Associative vs. topographical accounts of the immediate shock-freezing deficit in rats: Implications for the response selection rules governing species-specific defensive reactions. Learning and Motivation, 17, 16-39.

Fanselow, M. S. (1990). Factors governing one-trial contextual conditioning. Animal Learning \& Behavior, 18, 264-270.

Fanselow, M. S., DeCola, J. P., De Oca, B. M., \& Landeira-Fernandez, J. (1995). Ventral and dorsolateral regions of the midbrain periaqueductal gray (PAG) control different stages of defensive behavior: Dorsolateral PAG lesions enhance the defensive freezing produced by massed and immediate shock. Aggressive Behavior, 21, 63-77.

Fanselow, M. S., DeCola, J. P., \& Young, S. L. (1993). Mechanisms responsible for reduced contextual conditioning with massed unsignaled unconditional stimuli. Journal of Experimental Psychology: Animal Behavior Processes, 19, 121-137.

Fanselow, M. S., Landeira-Fernandez, J., DeCola, J. P., \& Kim, J. J. (1994): The immediate-shock deficit and postshock analgesia: Implications for the relationship between the analgesic CR and UR. Animal Learning \& Behavior, 22, 72-76.

Fanselow, M. S., \& Lester, L. S. (1988). A functional behavioristic approach to aversively motivated behavior: Predatory imminence 
as a determinant of the topography of defensive behavior. In R. C. Holles and M. D. Beecher (Eds.), Evolution and learning (pp. 185-212). Hillsdale, NJ: Erlbaum.

Fox, M. W. (1969). Ontogeny of prey-killing behavior in Canidae. Behaviour, 35, 259-272.

Gallup, G. G., Jr. (1977). Tonic immobility: The role of fear and predation. Psychological Records, 27, 41-61.

Hoffman, H. S., \& Fleshler, M. (1962). A relay sequencing device for scrambling grid shock. Journal of the Experimental Analysis of Behavior, 5, 329-330.

Hunt, H. F., \& Otis, L. S. (1953). Conditioned and unconditioned emotional defecation in the rat. Journal of Comparative and Physiological Psychology, 46, 378-382.

Kaufman, D. W. (1974). Differential predation on active and inactive prey by owls. Auk, 91, 172-173.

Kiernan, M. J., \& Westbrook, R. F. (1993). Effects of exposure to a to-be-shocked environment upon the rat's freezing response: Evidence for facilitation, latent inhibition, and perceptual learning. Quarterly Journal of Experimental Psychology, 46B, 271-288.

Kiernan, M. J., Westbrook, R. F., \& Cranney, J. (1995). Immediate shock, passive avoidance, and potentiated startle: Implications for the unconditioned response to shock. Animal Learning \& Behavior, 23, 22-30.

Landeira-Fernandez, J., Fanselow, M. S., DeCola, J. P., \& Kim, J. J. (1995). Effects of handling and context preexposure on the immediate shock deficit. Animal Learning \& Behavior, 23, 335-339.

Lubow, R. E. (1989). Latent inhibition and conditioned attention theory. New York: Cambridge University Press.

Maes, J. H. R., \& Vossen, J. M. H. (1992). One-trial aversive conditioning on contextual cues: Effects of time of shock presentation on freezing during conditioning and testing. Bulletin of the Psychonomic Society, 30, 403-406.
McAllister, W. R., \& McAllister, D. E. (1971). Behavioral measurement of conditioned fear. In F. R. Brush (Ed.), Aversive conditioning and learning (pp. 105-179). New York: Academic Press.

McAllister, W. R., McAllister, D. E., Scoles, M. T., \& Hampton, S. R. (1986). Persistence of fear-reducing behavior: Relevance for the conditioning theory of neurosis. Journal of Abnormal Psychology, 95, 365-372.

McLaren, I. P. L., Kaye, H., \& Mackintosh, N. J. (1989). An associative theory of the representation of stimuli: Applications to perceptual learning and latent inhibition. In R. G. M. Morris (Ed.), Parallel distributed processing: Implications for psychology and neurobiology (pp. 102-130). Oxford, England: Clarendon Press.

Muller-Velten, H. (1966). Uber den angstgeruch bei der hausmaus [On the fear-odor in the house mouse]. Zeitschrift fur vergleichende Physiologie, 52, 401-429.

Runyon, R. P. (1954). The role in avoidance learning of odors produced by stressed rats. Unpublished doctoral dissertation, Yale University, New Haven.

Spear, N. E., Miller, J. S., \& Jagielo, J. A. (1990). Animal memory and learning. Annual Review of Psychology, 41, 169-211.

Valenta, J. G., \& Rigby, M. K. (1968). Discrimination of the odor of stressed rats. Science, 161, 599-601.

Van Hemel, P. E., \& Colucci, V. M. (1973). Effects of target movement on mouse-killing attack by rats. Journal of Comparative and Physiological Psychology, 85, 105-110.

Westbrook R. F., Good, A. J., \& Kieman, M. J. (1994). Effects of the interval between exposure to a novel environment and the occurrence of shock on the freezing responses of rats. Quarterly Journal of Experimental Psychology, 478, 427-446.

Submitted April 1996

Revised December 1996

Accepted December 20, 1996 